\title{
COMPETÊNCIAS EMPREENDEDORAS EM FRANQUIAS: ESTUDO DE MULTICASOS EM SERGIPE
}

\author{
Maísle Alves Moraes de Souza- Mestrado em Administração da UFS -PROPADM ${ }^{1}$
} Rivanda Meira Teixeira- Mestrado em Administração da UFS -PROPADM²

Resumo: O objetivo deste estudo foi analisar as competências empreendedoras de dirigentes de unidades franqueadas a partir do modelo adaptado de Man e Lau (2000). Trata-se de uma pesquisa qualitativa, exploratória e descritiva. A estratégia adotada foi o estudo de casos múltiplos através de entrevistas semiestruturadas com três empreendedores. Os resultados deste estudo indicam que algumas diferenças e semelhanças foram verificadas, mas todos apresentaram elementos que caracterizaram a existência das competências de relacionamento, competências conceituais, competências de organização, competências estratégicas, competências de comprometimento e de apoio. Em relação às competências de oportunidade, apesar da maioria dos elementos em análise terem sido identificados, nem sempre elas são praticadas diretamente pelos empreendedores em questão, em razão do modelo de negócios de franchising.

Palavras-chave: Competências Empreendedoras; Franchising.

\section{ENTREPRENEURIAL COMPETENCIES IN FRANCHISES: MULTICASE STUDY IN SERGIPE}

\begin{abstract}
The aim of this study was analyze the entrepreneurial competencies of leaders of franchising units from the adapted model developed by Man and Lau (2000). This is a qualitative, exploratory and descriptive research. The strategy adopted was the multiple case study by using semi-structured interviews with three entrepreneurs. The results of this study indicate that some differences and similarities were found, but all of them showed elements that characterized the existence of the relationship competencies, conceptual competencies, organizational competencies, strategic competencies, commitment competencies and supporting competencies. Regarding the opportunity competencies, although most elements analyzed had been identified, they are not always performed directly by the entrepreneurs in question, due to the business of franchising model.
\end{abstract}

Keywords: Entrepreneurial Competencies; Franchising.

\footnotetext{
${ }^{1}$ E.mail: maisleufs@gmail.com - Endereço: Universidade Federal de Sergipe - Av. Marechal Rondon s/n - Jd. Rosa Elze - São Cristóvão - CEP: 49100-000 - Sergipe

2 E.mail: rivandateixeira@gmail.com
}

SOUZA, M. A. M; TEIXEIRA, R. M. Competências Empreendedoras em Franquias: estudo de multicasos em Sergipe. Revista de Empreendedorismo e Gestão de Pequenas

Empresas, v. 2, n.2, p. 3-31, 2013. 


\section{Introdução}

O tema empreendedorismo pode ser abordado de diversas maneiras e de formas genéricas. Porém, uma das abordagens mais recorrente da literatura gerencial trata de estudos sobre as habilidades e competências empreendedoras e sua relação com a organização (COSTA; BARROS; CARVALHO, 2011). A abordagem por competências é uma maneira de se estudar características individuais que podem ser levadas à realização de tarefas de um cargo e ao sucesso organizacional (MAN; LAU, 2000). Um empreendedor, fazendo uso apropriado de suas competências, pode ter mais percepções estratégicas, oportunidades para inovação, crescimento dos negócios e da prestação de novos serviços ou produtos (MAN; LAN; SNAPE, 2008).

A fim de contribuir para um melhor conhecimento do tema, o presente estudo propõe analisar as competências empreendedoras de dirigentes de unidades franqueadas no Estado de Sergipe a partir do modelo conceitual adaptado de Man e Lau (2000). Justifica-se a realização deste estudo pela relevância da abordagem sobre competências empreendedoras e pela carência de estudos publicados nesta área. O modelo de negócios de franquias também foi escolhido pela sua importância neste contexto. Filion (1997) já apresentava o tema de franquias como um dos 25 temas mais dominantes no campo do empreendedorismo. Campos, Parellada e Palma (2012) reforçam que o franchising é uma das correntes de pesquisa em empreendedorismo que tem sido mais constante.

Nessa linha, o presente estudo caracteriza-se como de natureza qualitativa com delineamento exploratório-descritivo e utiliza-se do método estudo de casos múltiplos. $O$ instrumento para a coleta de evidências foi a entrevista semiestruturada aplicada a dirigentes de três unidades franqueadas localizadas no estado de Sergipe. Inicialmente, serão estudados conceitos sobre competências empreendedoras, alguns modelos e tipologias presentes na literatura e o contexto do setor de franquias. Em seguida, os procedimentos metodológicos da pesquisa são apresentados. Por fim, seguem os resultados e as conclusões do estudo. 


\section{Competências Empreendedoras}

O termo competência foi definido por Fleury e Fleury (2001, p. 188) como sendo "um saber agir responsável e reconhecido, que implica mobilizar, integrar, transferir conhecimentos, recursos e habilidades, que agreguem valor econômico à organização e valor social ao indivíduo". O conceito de competência engloba um "conjunto de conhecimentos, habilidades e atitudes, acreditando-se que os melhores desempenhos estão fundamentados na inteligência e personalidade das pessoas" (MAMEDE; MOREIRA, 2005, p. 4).

Embora a princípio o objeto de análise seja o indivíduo, é possível verificar, tanto na literatura acadêmica como na que fundamenta a prática administrativa, que a tarefa ou o conjunto de tarefas pertencentes a um cargo norteia o conceito de competência (MAMEDE; MOREIRA, 2005). Fleury e Fleury (2001, p. 187) mencionam ainda que a competência do indivíduo não é somente um conhecimento ou know-how específico. Ela precisa ser contextualizada, ou seja, comunicada e utilizada de forma eficiente.

Assim, o termo competência compreende a interação dos recursos inerentes ao indivíduo com os oriundos do meio ou do contexto em que atua, sendo que os recursos do indivíduo são "constituídos pelos saberes (teóricos, do meio e procedimentais); pelos saber-fazer (formalizados, empíricos, relacionais e cognitivos) e por seus recursos pessoais (aptidões ou qualidades, recursos fisiológicos e recursos emocionais)" (FEUERSCHÜTTE; GODOI, 2008, p. 5). Existe também a questão do querer agir, pois as competências são realmente realizadas quando atribuídas de um sentido que se refere ao significado que confere a um determinado propósito ou fato a enfrentar.

$\mathrm{Na}$ atualidade, a investigação de comportamentos que caracterizam uma atuação empreendedora vem buscando incorporar as considerações sobre o contexto das competências (LENZI, 2008; ZAMPIER; TAKAHASHI; FERNANDES, 2012). Da mesma forma, na visão de Lizote et al. (2012), as competências por si só não são mais suficientes para as organizações, sendo necessário que o funcionário apresente atitudes empreendedoras, ou seja, que implementem inovação, 
criatividade, persuasão e ousadia. Porém, este processo, tanto no Brasil como no exterior, ainda carece de maior rigor conceitual e instrumental pela falta de absorção de discussões recentes em áreas como estratégia, gestão de pessoas, relações do trabalho e educação (ZAMPIER; TAKAHASHI; FERNANDES, 2012).

As competências associadas às posturas empreendedoras auxiliam na compreensão de atributos que agregam valor na interação entre grupos internos e externos à organização. Isso acontece quando elas representam senso de identificação de oportunidades, capacidade de relacionamento em rede, habilidades conceituais, capacidade gerencial, facilidade de leitura de contextos, posicionamento de mercado e comprometimento com interesses individuais e organizacionais (MAMEDE; MOREIRA, 2005).

A junção de competências com ações empreendedoras é retratada por Snell e Lau (1994 apud ZAMPIER; TAKAHASHI, 2011, p. 569) ao definirem o termo como "corpo de conhecimento, área ou habilidade, qualidades pessoais ou características, atitudes ou visões, motivações ou direcionamentos que, de diferentes formas, podem contribuir para o pensamento ou ação efetiva do negócio". De acordo com a abordagem teórica apresentada por Vesala e Pyysiäinen (2008), competências empreendedoras estão a um nível acima de competências técnicas, profissionais ou de gestão, pois se relacionam com a criação, execução e o desenvolvimento de uma empresa.

Acontece que, segundo Vesala e Pyysiäinen (2008), a competência empreendedora não é uma característica isolada e sem ambiguidades. Ela faz parte de uma estrutura hierárquica que pode abranger diversos tipos de atividades e processos, desde o reconhecimento de uma oportunidade até a sua realização. A competência empreendedora, segundo Paiva Jr. et al. (2006), deve estar alinhada ao saber fazer, ao saber ser e ao saber relacionar-se para tornar possível a reflexão sobre como o novo dirigente pode orientar-se no ambiente de negócios.

Fazendo uso apropriado de suas competências, um empreendedor pode ter mais percepções estratégicas como mais oportunidades para inovação, crescimento dos negócios e da prestação de novos serviços ou produtos. Com os recursos disponíveis, ele também pode desenvolver melhores capacidades organizacionais, 
como redução de custos, qualidade e flexibilidade. E, finalmente, ele pode planejar e trabalhar para um desempenho de longo prazo (MAN; LAN; SNAPE, 2008).

Dentro do tema de competência empreendedora, alguns modelos foram desenvolvidos por autores preocupados com esta temática. Contudo, dois deles têm se destacado na literatura: os modelos de Cooley (1990) e o de Man e Lau (2000), melhor detalhados no tópico a seguir.

\section{Modelos de Competências Empreendedoras}

Em relação às competências empreendedoras, um modelo clássico é o de Cooley (1990). Ele é revisado e adaptado do modelo de competências de McClelland, sendo voltado especificamente para os empreendedores. Ele lista 10 características comportamentais ou competências empreendedoras próprias de empreendedores bem sucedidos: busca de oportunidade e iniciativa; persistência; comprometimento; exigência de qualidade e eficiência; correr riscos calculados; estabelecimento de metas; busca de informações; planejamento e monitoramento sistemáticos; persuasão e rede de contatos; independência e autoconfiança.

Este modelo foi adotado no Brasil no estudo de Morales (2004), realizado no estado de Santa Catarina, com o objetivo medir a intensidade com que os tipos psicológicos junguianos se relacionam com as competências para empreendedores do modelo de Cooley. A análise estatística dos resultados demonstrou uma baixa correlação entre as competências e os tipos psicológicos de Jung. Ou seja, não constitui uma alternativa relevante para o desenvolvimento de programas de capacitação ou de competências empreendedoras, apesar de poder ser utilizada para avaliar outros aspectos comportamentais relacionados ao desempenho laboral. O perfil dos empreendedores verificado por meio do modelo de competências proposto por Cooley apresenta a "Exigência de Qualidade e Eficiência" e "Planejamento e Monitoramento Sistemáticos" como pontos fracos.

Outro estudo que adotou o modelo de Cooley foi o de Lenzi et al. (2012), realizado em Santa Catarina com o objetivo de identificar as competências dos empreendedores corporativos ligados à administração pública. O parâmetro de 
competências veio dos estudos de Cooley integrados aos de Spencer Jr. \& Spencer e McClelland. O estudo foi realizado com 25 servidores públicos envolvidos no desenvolvimento de projetos inovadores na Prefeitura de Blumenau. Os resultados apontam como competências empreendedoras que mais se destacam: comprometimento; busca de informações; persistência; planejamento e monitoramento sistemático; persuasão; e rede de contatos.

Outras pesquisas empíricas também utilizaram o modelo de Cooley, porém aliadas a outro modelo de destaque na literatura, o de Man e Lau (2000). Desta forma, estes outros estudos serão apresentados posteriormente.

Baseando-se em estudos empíricos anteriores sobre competências empreendedoras, o modelo de Man e Lau (2000) categoriza seis áreas de competência que representam seis áreas distintas que definem comportamentos empresariais: competências de oportunidade, competências de relacionamento, competências conceituais, competências administrativas, competências estratégicas e competências de comprometimento. Man e Lau (2000) apontam ainda as competências de apoio, que tratam de alguns comportamentos que parecem ajudar na construção ou no reforço de competências existentes. Estas áreas de competência são definidas a seguir no quadro 1. 


\begin{tabular}{|c|c|}
\hline Áreas de competência & Definições \\
\hline $\begin{array}{l}\text { Competências de } \\
\text { oportunidade }\end{array}$ & $\begin{array}{l}\text { Podem ser divididas em três grupos: identificação, avaliação e busca de } \\
\text { oportunidades de mercado. As formas mais comuns incluem experiência } \\
\text { anterior de negócios, atividades promocionais e informações de mercado. }\end{array}$ \\
\hline $\begin{array}{l}\text { Competências de } \\
\text { relacionamento }\end{array}$ & $\begin{array}{l}\text { Construir, manter e utilizar relacionamentos de confiança com todos os } \\
\text { stakeholders da empresa; e possuir habilidades de comunicação e } \\
\text { negociação para a gestão de conflitos e para a tomada de decisões. }\end{array}$ \\
\hline $\begin{array}{l}\text { Competências } \\
\text { conceituais }\end{array}$ & $\begin{array}{l}\text { Experiência e habilidade de observação do empresário e a capacidade de } \\
\text { inovação em seu comportamento e avaliação de riscos associados com a } \\
\text { permanência no mercado desfavorável e a entrada de um novo mercado. }\end{array}$ \\
\hline $\begin{array}{l}\text { Competências de } \\
\text { organização }\end{array}$ & $\begin{array}{l}\text { São as habilidades e o conhecimento para executar as funções gerenciais } \\
\text { de planejar, liderar, motivar, delegar e controlar. Um empreendedor deve } \\
\text { ser bom em gerenciar recursos humanos, tecnológicos, financeiros e } \\
\text { físicos internos ou externos de uma forma sistemática e eficiente. }\end{array}$ \\
\hline $\begin{array}{l}\text { Competências } \\
\text { estratégicas }\end{array}$ & $\begin{array}{l}\text { Empresários competentes definem visões a longo prazo e metas de médio } \\
\text { prazo que sejam reais e ao seu alcance. Além disso, eles precisam fazer } \\
\text { estratégias frente a mudanças ambientais para enfrentar clientes e } \\
\text { concorrentes. Eles são também responsáveis por estimar a viabilidade } \\
\text { financeira de uma estratégia e controlar os resultados. }\end{array}$ \\
\hline $\begin{array}{l}\text { Competências de } \\
\text { comprometimento }\end{array}$ & $\begin{array}{l}\text { Orientam o empreendedor a avançar com o negócio. É preciso manter o } \\
\text { compromisso com o negócio desde o início, sustentar esforços durante as } \\
\text { crises internas ou externas, comprometer-se com os objetivos de longo } \\
\text { prazo da empresa, dedicar-se ao trabalho a maior parte do tempo, } \\
\text { comprometer-se com o pessoal e com as crenças e valores da empresa. }\end{array}$ \\
\hline $\begin{array}{l}\text { Competências de } \\
\text { apoio }\end{array}$ & $\begin{array}{l}\text { A aprendizagem é um elemento essencial. Empresários competentes são } \\
\text { capazes de aprender a partir de experiência do passado e do } \\
\text { conhecimento formal de livros e teorias, bem como a partir de falhas e } \\
\text { erros. Além disso, eles aprendem de forma seletiva e especificamente } \\
\text { sobre o que é essencial para seus papéis de trabalho. Um empreendedor } \\
\text { também deve ser bom em gerenciar seu próprio tempo adequadamente, } \\
\text { equilibrando com o trabalho, seus familiares, momentos para o lazer e a } \\
\text { saúde; gerir preocupações e estresse; e manter-se no princípio da } \\
\text { integridade, sem se envolver em atividades ilegais. }\end{array}$ \\
\hline
\end{tabular}

Quadro 1: Áreas de Competência Definidoras de Comportamentos Empresariais

Fonte: Adaptado de Man e Lau (2000)

O estudo de Man e Lau (2000) foi realizado em Hong Kong e teve o objetivo de investigar as competências empreendedoras de proprietários de pequenas e médias empresas do setor de serviços. Em relação a estudos anteriores no mesmo contexto, os resultados destacam as competências de apoio mesmo não estando diretamente relacionadas ao desempenho. Resultados de estudos anteriores também apresentam elevado grau de similaridade com as áreas de competência

SOUZA, M. A. M; TEIXEIRA, R. M. Competências Empreendedoras em Franquias: estudo de multicasos em Sergipe. Revista de Empreendedorismo e Gestão de Pequenas Empresas, v. 2, n.2, p. 3-31, 2013. 
propostas neste estudo, o que fornece mais evidências para a sua validade e parece sugerir que as competências empreendedoras podem ser influenciadas pelo ambiente sociocultural em torno do empresário.

No Brasil, alguns estudos foram realizados utilizando-se do modelo de Man e Lau (2000). Paiva Jr., Leão e Mello (2003) realizaram um estudo no eixo Rio-São Paulo com o objetivo de verificar quais áreas das competências empreendedoras mais se destacavam nos comportamentos de dirigentes de empresas brasileiras da nova economia. Os resultados indicaram uma maior relevância das competências conceituais, administrativas e da competência de equilíbrio entre trabalho e vida pessoal. Destaca-se que o planejamento formal não está devidamente presente nas práticas administrativas dos entrevistados.

O estudo de Mamede e Moreira (2005) delineou o perfil de competências de empreendedores portugueses e cearenses que investem em hotelaria no Ceará baseando-se também nas características comportamentais apresentadas por McClelland (1987). Os dois empreendedores apresentaram visão de oportunidade. Apresentaram também competências conceituais, pois demonstraram vontade de aprender, elevada capacidade de inovação e facilidade de assumir riscos. $O$ comprometimento dos objetivos pessoais em conjunto com a vida empresarial também foi apresentado por ambos.

Já sobre o relacionamento dos dirigentes com seus colaboradores, o empreendedor português realiza uma gestão baseada em uma relação mais aberta, o que não acontece com o empreendedor cearense que resume o contato com os seus colaboradores a obrigatórias reuniões mensais. O mesmo aconteceu em relação às competências estratégicas detectadas no perfil do empreendedor português, mas não percebidas no empreendedor cearense, que não possui estratégias claras e definidas.

Outro estudo que utiliza a pesquisa de Man e Lau (2000) é o de Dias, Nardelli e Boas (2008) que teve como objetivo identificar quais competências empreendedoras relacionava-se aos empreendedores ganhadores do TOP Empresarial. Os resultados reforçam a existência das competências de oportunidades, relacionamento, conceituais, administrativas, estratégicas, de 
comprometimento e as de suporte, ressaltando a importância das competências conceituais e de suporte.

Já Zampier (2010) realizou na cidade de Curitiba, a partir do modelo de competências empreendedoras de Man e Lau (2000) e de aprendizagem empreendedora de Politis (2005), um estudo que analisou como as competências empreendedoras de oportunidade e administrativas de proprietários/dirigentes de micros e pequenas empresas do setor educacional privado foram desenvolvidas por meio de um processo de aprendizagem empreendedora. Os resultados demonstram que a competência administrativa foi um pouco mais desenvolvida que a de oportunidade. Foi também possível verificar as inter-relações apontadas pela literatura entre o desenvolvimento de competências e a aprendizagem.

Minello et al. (2011) também utilizaram o modelo de Man e Lau (2000) ao verificarem se os proprietários das lojas de um shopping popular possuíam competências e/ou características empreendedoras. Os resultados destacam que a competência de oportunidade foi a que obteve maior média. Já associadas à visão do ambiente, a competência de avaliar e assumir riscos foi a que apresentou menor média e a associada à ação estratégica foi predominante. Além disso, a pesquisa permitiu identificar que não há, aparentemente, correlação entre os constructos competências e características empreendedoras.

Um estudo que trabalha com a utilização dos dois modelos de competências empreendedoras apresentados é o de Honma e Teixeira (2011), realizado na cidade de Curitiba-PR, que teve como objetivo analisar as competências empreendedoras dos proprietários de hotéis de pequeno porte, baseando-se também em referencial teórico de Fleury e Fleury (2001) e Zarifian (2001). Verificou-se que não existe, entre os entrevistados, uniformidade em relação aos sete conjuntos de competências do estudo. Destaca-se que as competências que os empreendedores consideram mais importantes são as de comunicação, mobilização e qualidade de vida.

Neste momento, vale lembrar que são as competências empreendedoras propostas por Man e Lau (2000) classificadas nas seis áreas de competências, além das competências de apoio, que servirão como referencial para este estudo com dirigentes de franquias no estado de Sergipe. Porém, antes de evidenciar os 
aspectos metodológicos e a pesquisa em si, faz-se necessária uma contextualização do setor objeto deste estudo.

\section{Contexto do Setor}

Antes de tudo, é preciso dizer que franchising é um formato de negócios recente que tem se desenvolvido de forma substancial no Brasil (ESPINHA; MACHADO; RODRIGUES, 2005). De acordo com a Associação Brasileira de Franchising - ABF (2012), do ano de 2001 ao ano de 2011 o faturamento do setor de franchising passou de 25 bilhões de reais para mais de 88 bilhões de reais, 0 número de redes passou de 600 para 2.031 redes, o número de unidades evoluiu de 51.000 para 93.098 unidades e a geração de empregos diretos contemplou de 459.000 para 837.882 postos de emprego.

O franchising é um modelo de negócio composto por partes legalmente distintas: o franqueador, detentor da marca e do conhecimento de gestão do negócio; e os franqueados, que são múltiplos agentes econômicos (SILVA; AZEVEDO, 2007). Os autores acrescentam que a relação estabelecida entre franqueado e franqueador é regida por um contrato em que o franqueador transfere o direito de uso e exploração de sua marca na produção ou venda de produtos ou serviços, determinando-se um período e uma localização geográfica específica.

Para o franqueado, os benefícios do valor da marca e do acesso à propaganda refletem nos ganhos de escala em marketing e em investimentos que dificilmente seriam alcançados de forma isolada (LUIZ et al., 2006). O franqueador pode também oferecer programas de treinamento, além de outros serviços como assistência técnica e comercial. Em contrapartida, ele recebe uma soma monetária fixa inicial juntamente com parte das vendas do franqueado. $O$ franqueado contribui com os recursos financeiros, sua habilidade gerencial ou conhecimento sobre 0 mercado local (SILVA; AZEVEDO, 2007).

É um negócio testado e aprovado disponível para quem esteja disposto a empreendê-lo de acordo com as condições estabelecidas pelo franqueador (ESPINHA et al., 2007). Por este motivo, o sistema pode ser considerado como uma 
forma alternativa de se inciar um negócio adotada por alguns empresários que se preocupam em reduzir incertezas e riscos, obtendo menores taxas de fracasso (UCBASARAN; WESTHEAD; WRIGHT, 2001; LUIZ et al., 2006). Vale ressaltar que, de acordo com a afirmação de Ribeiro e Prieto (2009), em relação a compartilhamento de custos e riscos no sistema de franquias, ambas as partes têm direitos e deveres, e é esse comprometimento individual que influencia no crescimento e no sucesso da empresa.

No entanto, Luiz et al. (2006) apontam alguns riscos na utilização do modelo de negócios de franquias. Para os franqueadores, pode existir a perda de valor da marca à medida que os padrões específicos não são seguidos tanto para produtos, quanto para processos ou serviços, bem como a disseminação indevida do conhecimento inerente à empresa. Para os franqueados, ter várias unidades de uma mesma franquia localizadas em uma mesma região implica em maior concorrência e menor incidência de lucros. Neste caso, pode acontecer de o franqueador pode não investir na sua marca e no desenvolvimento de novos produtos, levando à estagnação da franquia e perda do posicionamento competitivo.

Mas de uma maneira geral, o sistema de franchising é tido como um modelo de negócios que atende tanto a necessidade de gerar emprego e renda, já que a escassez de empregos no Brasil é uma realidade, quanto a de estabelecer negócios que já contenham suporte adequado (ROCHA, 2010). Desta forma, além de representar uma parte importante da economia, é também um fenômeno central no empreendedorismo (MICHAEL, 2003).

A princípio, o franchising pode não parecer se enquadrar no contexto do empreendedorismo, já que o sistema possui um formato pré-definido (ESPINHA; MACHADO; RODRIGUES, 2005). Para alguns autores, a franquia é a antítese da inovação e representa a homogeneização de uma cultura comercial, responsável pela falta de variedade em uma série de setores do varejo (KAUFMANN; DANT, 1999). Porém, Espinha, Machado e Rodrigues (2005) afirmam que esse sistema de negócios não representa uma restrição à ação empreendedora e que é consenso entre vários outros autores que é empreendedor o indivíduo que busca oportunidades e reorganiza recursos de forma a explorá-los e aproveitá-los.

SOUZA, M. A. M; TEIXEIRA, R. M. Competências Empreendedoras em Franquias: estudo de multicasos em Sergipe. Revista de Empreendedorismo e Gestão de Pequenas 
empreendedorismo também pode ocorrer, segundo o GEM (2012), com a expansão de um negócio já existente. Kaufmann e Dant (1999) também corroboram com esta afirmação, pois colocam que a associação entre franchising e o empreendedorismo muitas vezes é formalmente institucionalizada dentro de universidades, centros ou institutos de empreendedorismo.

É neste contexto que o presente estudo será realizado, analisando as competências empreendedoras de dirigentes de unidades franqueadas localizadas no estado de Sergipe, baseando-se nas categorias de análise do modelo conceitual de Man e Lau (2000) já apresentado.

\section{Aspectos Metodológicos}

O presente estudo pode ser caracterizado como qualitativo, de natureza exploratório-descritiva. Um estudo exploratório, segundo Saunders, Lewis e Thornill (2000), é utilizado quando o pesquisador deseja esclarecer a sua compreensão de um problema. Para Neuman (1997), pode ser o primeiro estágio de uma sequência de estudos, sendo que o seu foco a princípio é amplo e vai se restringindo com o desenvolver da investigação.

Já uma pesquisa descritiva apresenta um quadro de detalhes específicos sobre um determinado fenômeno. O pesquisador começa com um assunto bem definido e conduz a pesquisa para descrevê-lo cuidadosamente (NEUMAN, 1997). Saunders, Lewis e Thornill (2000) ressaltam que neste tipo de estudo não basta descrever. É preciso chegar a conclusões, avaliar dados e sintetizar ideias.

Em relação ao tratamento do tempo é um estudo transversal, que acontece quando uma pesquisa ocorre analisando em detalhes um determinado momento (SAUNDERS; LEWIS; THORNILL, 2000; NEUMAN, 1997). As entrevistas foram realizadas no mês de janeiro de 2012 e as evidências coletadas referem-se apenas a este momento. A estratégia de pesquisa utilizada foi 0 de estudo de casos múltiplos. Segundo Yin (2005), esse tipo de método tem ganhado muitos adeptos, principalmente porque possibilita o estabelecimento de comparações e a obtenção de resultados mais robustos, contribuindo para o aumento da validade do estudo. 
Desta forma, foram selecionadas três franquias que atenderam aos seguintes critérios: são unidades franqueadas localizadas no estado de Sergipe; e que seus dirigentes estivessem disponíveis e interessados em participar do estudo. Estes critérios atendem aos pré-requisitos para uma pesquisa poder ocorrer citados por Creswell (2010): ter participantes que estejam dispostos a contribuir com a pesquisa; e possuir recursos para a coleta e análise de dados.

As evidências foram coletadas por meio de entrevistas semiestruturadas que foram gravadas, transcritas e, posteriormente, seu conteúdo analisado. Para Yin (2005), a entrevista é uma das mais importantes fontes de informações para um estudo de caso. A análise dos casos foi feita utilizando a técnica de análise de conteúdo de Bardin (2008), um conjunto de técnicas de análise das comunicações com o objetivo principal de interpretá-las.

\section{Análise dos Resultados}

Os casos foram analisados baseando-se na caracterização das franquias, no perfil dos dirigentes e nas categorias analíticas do estudo: competências de oportunidade, competências de relacionamento, competências conceituais, competências de organização, competências estratégicas, competências de comprometimento e competências de apoio.

Em relação à caracterização das franquias e perfil dos dirigentes, as empresas A e B são recentes no mercado sergipano (fundadas em 2011) e a empresa $C$ iniciou suas atividades no ano de 2005. Todas as empresas pertencem ao setor do comércio, sendo que as empresas $A$ e $B$ comercializam os mesmos produtos (alimentos e bebidas) e a empresa C comercializa calçados, bolsas e acessórios. A quantidade de funcionários das empresas A, B e C é de 10, 17 e 5, respectivamente. Dois dos empreendedores possuem de 26 a 35 anos de idade (empresas B e C) e um possui de 36 a 45 anos. Todos possuem o mesmo grau de instrução (superior completo), porém em formações distintas (Administração, Direito e Turismo).

SOUZA, M. A. M; TEIXEIRA, R. M. Competências Empreendedoras em Franquias: estudo de multicasos em Sergipe. Revista de Empreendedorismo e Gestão de Pequenas 
Com relação às competências de oportunidade, observou-se na empresa A que a identificação, avaliação e busca da oportunidade de mercado são influenciadas pelas experiências profissionais anteriores do empresário, já que ele esteve à frente de outros empreendimentos. Importante mencionar também a existência de uma deficiência no mercado na época, pois não havia quase nenhuma empresa de alimentação saudável, inclusive no bairro onde ele pretendia instalar a empresa. Para ele, existe também um movimento em prol da saúde que ajuda o setor a se tornar uma boa oportunidade de negócio.

No caso do empreendedor da empresa B, o negócio foi percebido como uma oportunidade porque existia também a mesma lacuna de mercado: "Aracaju necessitava de um produto leve, saudável, prático. As pessoas tem pouco tempo, trabalham o dia todo". Ele afirma que continua sempre buscando essas informações de mercado, pensando em melhorias, mesmo isso estando mais vinculado ao franqueador: "Tem que seguir as normas principais, mas dentro da loja cada um administra como quer".

Tratando-se, por sua vez, da empresa C, a experiência anterior de familiares influenciou na identificação da oportunidade de negócio, uma vez que o cônjuge do entrevistado já possuía um empreendimento. Outra experiência que também influenciou é o fato de que ela já conhecia e gostava da marca como consumidora.

Em relação a clientes, concorrentes e atividades promocionais, o empreendedor da empresa A parece avaliá-los a todo o momento. Algumas ações não podem ser simplesmente implementadas, pois existem as implicações em relação à franquia, mas o dirigente afirma que consegue implementar algumas mudanças que não venham a interferir no padrão da empresa. Acontecem atividades promocionais relacionadas a descontos, campanhas em períodos comemorativos, participação em sites de compras coletivas, panfletagem (feita inclusive pelo próprio dono), dentre outros.

Já a concorrência e as atividades promocionais, na visão do empreendedor B, são consideradas importantes de serem avaliadas. É um trabalho feito por núcleos de trabalho da franquia. Todo mês são pagos royalties sendo que um percentual é só para propaganda. A franquia se responsabiliza totalmente pela 
divulgação do produto, o que na opinião do entrevistado é feito com muita competência. Os franqueados só fazem receber os feedback's e as ações que serão implementadas. Porém, em relação aos clientes, o entrevistado acredita que mudanças de ambiente podem se tornar oportunidades de melhorias. Ele se recorda de um momento em que ocorria muita demora na fila e muitas reclamações. Isso acabou gerando esforços de melhoria no atendimento. Quanto a seguir tendências, ele acredita estar em um segmento em que cuidar da saúde tornou-se uma tendência.

No caso da empresa C, a avaliação dos clientes e da concorrência em questão também ocorre, mas é feita pela franquia. O mesmo acontece com as atividades promocionais, como alega:

É pago $3 \%$ de royalties que é a taxa de propaganda e marketing. Então o banner são eles que mandam, quando tem alguma promoção vinculada ao cinema, eles que mandam os convites, tudo por eles. Vitrine de dia das mães, a gente compra por eles [...].

A empresa também pertence a um segmento que é marcado pelas tendências, como comenta o empreendedor: "A empresa tem blog, participa de rede social, tem comunicados que sempre vê que eles passam para os funcionários lerem, eles têm que estar sabendo de tudo que tem na moda".

Assim, os elementos que se relacionam às competências de oportunidade não identificados foram: a influência da experiência anterior de negócios no caso da empresa $B$, já que o empreendedor havia apenas atuado em sua área de formação (Direito); o fato da empresa C não ter iniciado com o intuito de preencher uma lacuna de mercado; e a crença do empreendedor da empresa $A$ de que o seu negócio não segue tendências de forma expressiva. Destaca-se o empreendedor da empresa A que, apesar de muitas vezes limitado pelo sistema da franquia, constantemente parece estar atento a realizar atividades promocionais e implementar possíveis melhorias por meio da avaliação de clientes e da concorrência. Isto reforça o que Silva e Azevedo (2007) afirmaram quanto à contribuição do franqueado não somente com recursos financeiros, mas também

SOUZA, M. A. M; TEIXEIRA, R. M. Competências Empreendedoras em Franquias: estudo de multicasos em Sergipe. Revista de Empreendedorismo e Gestão de Pequenas 
com sua habilidade gerencial ou conhecimento sobre o mercado local (SILVA; AZEVEDO, 2007).

Já em relação às competências de relacionamento, o empreendedor da empresa $A$ avalia que são as relações que o ajudam a resolver problemas e tomar decisões. A sua relação com os funcionários ocorre por meio de uma boa comunicação, apesar de considerar uma relação difícil, como explica: "Eu me dou bem com todo mundo, mas às vezes tem momentos de stress". Ele adota mais as conversas pessoais e informais. Quanto ao fator confiança em relação aos funcionários, ele avalia existir em parte. Informou ter adotado um sistema de câmeras na loja (inclusive uma fica direcionada ao caixa) para poder controlar tudo o que os funcionários estão fazendo.

Mas além da esposa que trabalha com ele no negócio, existe um funcionário que ele também confia bastante e que realiza algumas atividades, como pedido de compras, de materiais e pagamento de contas. Em relação a passar confiança aos clientes sobre os produtos comercializados, ele aposta na higiene, na qualidade, em produtos que utilizem materiais frescos, colhidos geralmente na noite anterior, sem trabalhar com ingredientes processados. Com os fornecedores ele alega já ter tido alguns problemas, mas a relação no geral é boa. A habilidade de comunicação é notória, dando-se uma atenção especial à forma de se relacionar com o seu cliente, como destaca o empreendedor:

Recebo todos os clientes, se possível, na porta. Faço atendimento, apresentação da loja, do cardápio, pergunto nome dos clientes [...]. Hoje eu sei o nome de quase 400 a 500 clientes, sei o nome dos filhos, em alguns casos, da mãe, da esposa, do esposo, já sei o produto que alguns gostam mais [...]. Alguns clientes gostam de conversar... Tem cliente que pede pra eu sentar à mesa pra conversar com ele.

Quanto à empresa $\mathrm{B}$, a comunicação com os funcionários acontece por meio de reuniões que ocorrem uma vez por mês ou extraordinariamente quando há alguma necessidade. Os que são supervisores e gerentes o contato acontece a todo o momento com o intuito de sempre manter a qualidade dos serviços. Existe uma relação de confiança com os funcionários e sobre delegar atividades, ele trabalha 
com um irmão que é seu sócio e que costuma assumir a parte de rotinas de pessoal. A relação de confiança com os clientes sobre os produtos comercializados ele acredita que já acontece por meio da marca consolidada da franquia. "É a vantagem da franquia. O cliente já conhece, já sabe que é uma marca conceituada. Ele já sabe que tem um bom produto".

A relação com os fornecedores também fica a cargo da franquia que possui núcleos que fazem negociações diretamente, como destaca: "Eles tentam ao máximo qualidade e preço". O entrevistado também acredita possuir habilidades de comunicação e de negociação em seu empreendimento. Ele exemplifica com os aproximadamente $10 \%$ de compra de materiais que necessita realizar no mercado local: "Eu procuro muito pela qualidade, preço, discuto muito com os fornecedores locais pra chegar a um denominador comum que seja bom para os dois, principalmente para a empresa".

No caso da empresa C, o empreendedor alega que até pelo fato de serem somente 4 funcionários o relacionamento é considerado bom. As informações necessárias são sempre passadas em reuniões periódicas (pelo menos uma vez no mês) e através de revistas que a própria franquia envia. Se precisar de uma reunião mais informal e pessoal também é feito. Ele alega existir muita confiança na relação com os funcionários, principalmente com a gerente, até porque ele necessita às vezes estar fora da empresa por ter um filho pequeno com idade de três anos. Em relação aos clientes, o empreendedor explica que costuma passar confiança sobre os produtos comercializados utilizando da estratégia das próprias funcionárias utilizarem o produto: "As funcionárias têm eles no pé para poder mostrar, elas sabem dizer as características do produto pelos estudos. [...] Elas gostam da marca, usam, então é mais fácil de explicar e vender". Outras relações consideradas importantes são com as transportadoras e com a administração do espaço onde a loja está localizada. O empreendedor acredita possuir habilidades de comunicação, como destaca: "Eu gosto de estar lá embaixo, falo com o cliente, eu pergunto, eu converso, o que às vezes o funcionário não faz. Então quando eu estou lá embaixo com certeza vende um pouco mais do que quando eu estou fora”.

SOUZA, M. A. M; TEIXEIRA, R. M. Competências Empreendedoras em Franquias: estudo de multicasos em Sergipe. Revista de Empreendedorismo e Gestão de Pequenas 
Assim, os elementos não identificados relacionados às competências de relacionamento foram: o empreendedor da empresa $A$, que evita reuniões formais e não tem tanta confiança nos funcionários; e o empreendedor da empresa $C$ que não acredita possuir tantas habilidades de negociação, inclusive pelo fato de não tentar influenciar a franqueadora em algumas ações de melhorias.

Quanto às competências conceituais, observou-se que o empreendedor da empresa A costuma agir pela intuição. Se tiver que tomar uma decisão ele faz uma breve análise e obtém logo um posicionamento. É perceptível também o seu comportamento inovador. A sua loja conseguiu, segundo destaca, inovar no cardápio, o que é difícil de conseguir uma autorização do franqueador: "A gente tem alguns produtos que só quem tem é a filial de Aracaju”. Ele acredita inovar também no atendimento, pois afirma: "Em Aracaju, em nenhum restaurante você é atendido pelo dono".

Em relação ao empreendedor da empresa $\mathrm{B}$, ele se caracteriza como observador e intuitivo. Alega trabalhar muito em prol da qualidade e do aumento do grau de excelência e ter estas características de observação e intuição sempre o ajuda a achar detalhes que geram melhorias. Também considera ter um comportamento inovador: "Não posso deixar as coisas paradas. Gosto de estar sempre causando choques". Já o empreendedor da empresa C acredita possuir a habilidade de observação e intuição.

Desta forma, o elemento de análise das competências conceituais não identificado foi o fato do empreendedor da empresa $C$ perceber não possuir um comportamento inovador, inclusive pelo fato já citado anteriormente de não tentar influenciar a franqueadora em algumas ações de melhorias.

Com relação às competências de organização, o empreendedor da empresa A diz se envolver com todas as atividades da empresa, mas seu papel maior está ligado à área financeira, de recursos humanos e de promoção da empresa. Uma atividade que ele alega sentir muito prazer de desempenhar é a de garçom, como comenta: "Eu adoro! Sou louco de paixão por servir mesa. Pouca gente acredita nisso". Os funcionários possuem metas que na verdade são para todos do restaurante. Existem também regulamentos e procedimentos por escrito na 
empresa e sempre que possível, os funcionários são encaminhados para cursos, como na área de segurança alimentar. Quanto às suas recompensas, é fornecido auxílio alimentação e a taxa de serviço é dividida por igual para todos. O restaurante também aparenta ter uma boa estrutura física.

Quanto à empresa $\mathrm{B}$, o entrevistado se envolve em todas as atividades da empresa, mas costuma delegar responsabilidades. Suas atribuições estão mais relacionadas com a área financeira. Os funcionários possuem metas diárias e mensais que se referem a número de faltas, aumento das vendas, diminuição de custos, entre outras. A empresa utiliza um sistema considerado uma ferramenta importantíssima para o acompanhamento dos resultados e os funcionários, segundo o entrevistado, eles ficam sempre antenados aos seus desempenhos. Os funcionários passam por ações de treinamento logo que iniciam suas atividades e recebem benefícios como o plano de saúde e, em breve, o plano odontológico. Além da parte financeira, o empresário acredita passar para eles motivação com a sua postura na empresa.

Em relação à estrutura física, ele considera que possuem recursos satisfatórios e todo mês ela passa por uma averiguação da franquia. O uso de tecnologia restringe-se ao sistema da franquia já citado e os critérios de definição dos investimentos dos recursos financeiros são estudados pela franquia. Ele destaca que nada é feito de forma aleatória, pois existe muito estudo. Quanto aos procedimentos a serem adotados pelos funcionários, eles seguem a linha da loja que é passada pelo gerente. $O$ dirigente afirma que tem outra loja em que estão fazendo um teste em ter regulamentos por escrito: "Não adianta só falar [...] e no outro dia esquecer. [...] Se der certo, vamos aplicar nas outras lojas".

Em relação ao empreendedor da empresa $C$, ele alega participar de todas as atividades da empresa, mas consegue também delegar: "a gerente hoje consegue fazer tudo. É quem manda relatório, quem faz pedido. Então é uma forma de confiança". Em relação a metas, elas existem e são vinculadas às vendas e ao número de clientes atendidos. Inclusive quem consegue atingir ganha uma porcentagem maior de comissão. É feito acompanhamento, até porque eles têm metas por semana, como comenta: "a loja é pequena, são só quatro funcionários, 
então é mais fácil saber o que está acontecendo quando as vendas estão baixas". Quanto a ações de treinamento e desenvolvimento, ocorrem de seis em seis meses com a supervisora da franquia e as ações atingem a dirigente, a gerente e as vendedoras.

Para motivar ou recompensar seus funcionários, a entrevistada aposta no ambiente de trabalho e na relação de abertura e respeito que eles possuem. Além disso, tem as comissões e o direito de retirar mercadorias com desconto. Às vezes são feitas outras ações também ligadas às vendas, como comenta: "dezembro teve celular. Quem vendesse mais, ganharia”. A estrutura física é avaliada como boa pelo entrevistado, por considerar que possui um espaço grande para guardar mercadorias e um local para atendimento bonito, bom de trabalhar e espaçoso. Existe a supervisão da franquia também que comparece periodicamente para averiguar e apresentar relatório sobre a estrutura em geral.

A empresa possui um sistema que é da própria franquia e serve para comunicação entre as lojas, a realização de compras, trocas de e-mail e informações sobre as vendas. Geralmente os recursos financeiros são investidos em mercadorias, como afirma: "se ficarem poucas as vendas param. Nesse ramo, todo o dinheiro é para o estoque ficar bom e a loja não ficar vazia". Existem procedimentos formais escritos na relação da franqueada com o franqueador. Com relação aos funcionários há procedimentos como, por exemplo, o uso do uniforme e a aparência das unhas e do cabelo.

Assim, os elementos relacionados às competências de organização não detectados foram o não uso de tecnologia e a falta de uma análise mais elaborada de investimentos financeiros pelo empreendedor da empresa A. Destaca-se que alguns treinamentos realizados para os funcionários da empresa $A$ são de iniciativa do empreendedor. $E$ ressalta-se que os treinamentos que ocorrem na empresa $B$ limitam-se ao momento de ingresso do funcionário.

Quanto às competências estratégicas, o empreendedor informou que existem objetivos para este ano, mas que eles ainda seriam discutidos em reunião, quando será feita uma avaliação do negócio. Objetivos em longo prazo existem, mas o entrevistado preferiu não comentar do que se tratam. Porém, ele acredita que são 
realistas e alcançáveis. O seu posicionamento de mercado varia, segundo o empreendedor, de acordo com o produto. Mas ele se considera em geral bem posicionado no mercado. O perfil do seu cliente inicialmente era de classe A. Hoje, tem pontualmente $D$, mas a maioria é $B$ e $C$. O empreendedor também acredita conhecer seus principais concorrentes. Para o produto A considera ter só um concorrente, mas que tem um cardápio diferenciado e preço maior. Em relação ao produto B ele considera ter um concorrente que é imbatível. Sua estratégia é tentar fazer um preço promocional. O produto C não considera ter concorrente, pois acredita ter variedade e qualidade. O produto $\mathrm{D}$ tem um concorrente.

Já o empreendedor da empresa $B$ alega que seus objetivos constantes é a melhoria do atendimento e da qualidade, para conseguir ganhar cada vez mais clientes, como afirma: "A gente quer a excelência. Chegar a $100 \%$ é difícil. Mas estamos tentando". Em longo prazo ele pretende abrir mais lojas. Considera seus objetivos alcançáveis, pois cada passo é bem estudado. Quanto ao posicionamento da sua empresa no mercado, considera estar muito bem ranqueado: "Apesar de termos concorrentes, ao mesmo tempo não temos. Porque o nosso nicho é diferenciado. Digamos que é um produto mais saudável. O meu principal concorrente disputa mais com outras empresas". Ele acredita que o seu negócio atinge um público mais jovem, voltado mais para a saúde e o esporte, e a franquia com certeza pensa nesse perfil ao traçar seus esforços. As estratégias com os concorrentes geralmente vinculam-se ao fator preço. $O$ planejamento e acompanhamento de resultados vão sendo trabalhados mensalmente, comparandoos com o ano anterior. Apesar de estar vinculado à franquia, ele já conseguiu implementar algumas estratégias por necessidade do seu ambiente de mercado. Exemplificou com um momento em que sua loja passaria a ter mais contato com um público de poder aquisitivo um pouco menor e que conseguiu reduzir os preços para atender a este público: "E surtiu resultado. Compensou com o volume de vendas".

Em relação aos objetivos do empreendedor da empresa $\mathrm{C}$, estes se relacionam com o aumento das vendas, inclusive os de longo prazo. O intuito é permanecer sendo uma marca conhecida, com clientes fidelizados que sempre voltam a comprar, como explica: "E a gente tem isso bastante. Clientes que 
compram só com a nossa empresa. Então eu acho que é só continuar". Quanto ao posicionamento, o empreendedor avalia estar em primeiro lugar quanto ao seu produto A pelo conforto que apresenta. Quanto ao produto B, o empreendedor comenta: "a concorrente A é imbatível. É que é um mercado que tem muitas lojas. Eu acho que eu ficaria em terceiro, quarto lugar". Em relação ao perfil dos seus clientes, ela acredita que são pessoas que querem estar na moda, com produtos que seguem tendência, são bonitos, mas pagando pouco, já que ela avalia que seus preços são mais em conta que os da concorrência. Quanto aos concorrentes, a gerente fica mais atenta na busca de informações, visitando blogs, indo às lojas, vendo quando eles estão com promoção, para que a empresa adote também, como explica: "a gente tenta superar no atendimento, porque o produto tem às vezes até igual. O preço da empresa é bom, mas acho que o atendimento é primordial”. A viabilidade financeira de uma estratégia é sempre verificada junto ao cônjuge e à gerente.

Desta forma, os elementos relacionados às competências estratégicas não presentes nas empresas estudadas foram: o fato do empreendedor da empresa $\mathrm{C}$ não traçar objetivos em longo prazo; o entrevistado da empresa A geralmente não realiza análises de viabilidade financeira; e coincidentemente todas as três empresas não praticam ações de responsabilidade social.

Em relação às competências de comprometimento, o entrevistado da empresa A destaca-se pela dedicação ao empreendimento. Ele respondeu estar em média 12 horas por dia de segunda a segunda dedicado ao empreendimento. Em seu trabalho, procura superar dificuldades, como explica: "Hoje em dia eu sorrio pra o problema, esqueço ele e vou pra solução". Seu sentimento também é de comprometimento e responsabilidade pelos seus funcionários. Suas principais crenças, que são passadas para os funcionários, estão na importância da higiene e do bom atendimento.

Quanto ao empreendedor da empresa B, ele afirma dedicar-se todos os dias ao trabalho, geralmente pelas manhãs e noites. E com trabalho e ações estratégicas sempre conseguiu ultrapassar dificuldades e obstáculos encontrados na gestão do empreendimento. Ele também afirma sentir-se comprometido e responsável pelos 
seus funcionários: "O funcionário é a alma da empresa". Quanto aos principais valores da empresa, estes se relacionam principalmente com o atendimento ao cliente e comportamento padrão, como comenta: "Eu sempre falo... você pode ir num local que a comida não seja tão boa, mas se for bem atendido, você volta. Agora se a comida for boa e você for mal atendido, você não volta".

Em relação ao empreendedor da empresa $C$, ele costuma dedicar-se de quatro a seis horas por dia ao trabalho nos dias de segunda à sexta. $O$ empreendedor afirma que são muitas as dificuldades encontradas diariamente, mas ele sente-se comprometido em resolvê-los, inclusive quando relacionados a funcionários, pelos quais se sente responsável. Os principais valores do empreendimento, na percepção do empreendedor, são a humildade e o bom atendimento:

A gente vê muito em outras lojas a pessoa te olhar de cima a baixo, não te tratar bem. [...] E eu sempre dou exemplo. Eu sempre que estou no atendimento eu trato qualquer um da mesma forma. Elas sempre são muito simpáticas, eu sempre passo para elas não diferenciarem ninguém, para atenderem todo mundo da mesma forma.

Assim, em relação às competências de comprometimento, destaca-se a dedicação que o empreendedor da empresa $A$ oferece ao seu negócio demonstrando total comprometimento.

Por fim, quanto às competências de apoio, o empreendedor da empresa $A$ costuma adquirir aprendizados através das experiências do trabalho, dos erros e acertos cometidos. Quanto a sua forma de gerenciar o estresse no trabalho, afirma que já foi pior. Hoje, afirma estar razoável, pois aprendeu a lidar mais com os problemas. Já os aprendizados do dirigente da empresa B costumam ser adquiridos lendo muito sobre a área, participando de reuniões regionais, nacionais e trocando experiências com outros franqueados. Ele costuma também fazer cursos específicos voltados para o seu setor. Quanto à administração do tempo, afirma conseguir conciliar com a família, lazer e saúde: "Tem que ter tempo pra tudo porque se você não tiver equilíbrio, uma coisa atrapalha na outra".

SOUZA, M. A. M; TEIXEIRA, R. M. Competências Empreendedoras em Franquias: estudo de multicasos em Sergipe. Revista de Empreendedorismo e Gestão de Pequenas 
Em relação ao nível de stress no trabalho, ele diz que já foi mais estressado no início, mas afirma que "hoje em dia, com a experiência, você vai aprendendo com os erros". E, por sua vez, o empreendedor da empresa $C$ alega que costuma adquirir aprendizados lendo, estudando e interagindo com outras pessoas do ramo de negócios, como afirma: "Tem revistas, tem programas de televisão como Pequenas empresas, grandes negócios, o Mundo S/A que é muito bom... é vendo exemplos, experiências, vendo aquilo que dá certo e você faz de novo". Quanto à administração do tempo ele informou também conseguir dedicar-se muito bem à família, ao lazer e à saúde. E o nível de stress no trabalho é considerado baixo pelo entrevistado: "Cada dia resolve o que da pra resolver. Não levo nada pra casa".

Por fim, os elementos analisados das competências de apoio em relação aos três empreendedores não encontrados foram: não ocorre a aprendizagem dos empreendedores das empresas A e C através de cursos formais; e o empreendedor da empresa A não consegue ter tempo adequado para a família, o lazer e os cuidados com a saúde. O empreendedor afirma serem consequências da extrema dedicação que ele considera necessária no trabalho.

\section{Considerações Finais}

Este estudo buscou, por meio do estudo de múltiplos casos, analisar as competências empreendedoras de dirigentes de unidades franqueadas do estado de Sergipe tomando por base as categorias de análise do modelo conceitual de Man e Lau (2000). Como no estudo de Honma e Teixeira (2011), não existiu uniformidade entre os entrevistados em relação a todos os elementos de análise. Algumas diferenças e semelhanças foram verificadas, mas todos apresentaram, de alguma forma, elementos que caracterizaram a existência das seguintes competências empreendedoras em estudo: competências de relacionamento, competências conceituais, competências de organização, competências estratégicas, competências de comprometimento e competências de apoio.

Em relação às competências de oportunidade, ressalta-se que, apesar da maioria dos elementos em análise terem sido identificados, nem sempre eles são

SOUZA, M. A. M; TEIXEIRA, R. M. Competências Empreendedoras em Franquias: estudo de multicasos em Sergipe. Revista de Empreendedorismo e Gestão de Pequenas 
praticados diretamente pelos empreendedores em questão, em razão do sistema de franquias. No entanto, entende-se que, como também afirmou Espinha, Machado e Rodrigues (2005), esse sistema de negócios não representa uma restrição à ação empreendedora. Os empreendedores buscaram a oportunidade de ter esta competência melhor desenvolvida por meio do trabalho desenvolvido pelo franqueador.

Neste sentido, estes resultados parecem corroborar com os dos estudos empíricos (de Man e Lau, 2000), realizado em Hong Kong com proprietários de pequenas e médias empresas do setor de serviços, por reforçarem as competências empreendedoras propostas em seu modelo conceitual. Parecem similares também aos resultados do estudo de Dias, Nardelli e Boas (2008) entre empreendedores que ganharam o TOP Empresarial, onde se verificou a existência de todas as sete competências empreendedoras.

Considera-se que o presente estudo constitui uma pesquisa introdutória, podendo ser realizado com outras metodologias de pesquisa e com a aplicação em outros contextos de negócios e geográficos. Desta forma, os resultados apresentados podem ser melhor consolidados para possíveis generalizações.

\section{Referências}

ABF. ASSOCIAÇÃO BRASILEIRA DE FRANCHISING. Disponível em $<$ www.portaldofranchising.com.br>. Acesso em: 20 jan. 2013.

BARDIN, L. Análise de Conteúdo. RETO, Luís Antero; PINHEIRO, Augusto (Trads.). Lisboa: Edições 70 Ltda., 2008.

CAMPOS, H. M.; PARELLADA, F. S.; PALMA, Y. Mapping the Intelectual Structure of Entrepreneurship research: revisiting the invisible college. RBGN, São Paulo, v. 14, n. 42, p. 41-58, jan./mar., 2012.

COOLEY, L. Entrepreneurship Training and the Strengthening of Entrepreneurial Performance. Final Report. Contract No. DAN-5314-C-00-3074-00. Washington: USAID, 1990. 
COSTA, A. M.; BARROS, D. F.; CARVALHO, J. L. F. A Dimensão Histórica dos Discursos acerca do Empreendedor e do Empreendedorismo. Revista de Administração Contemporânea, Curitiba, v. 15, n. 2, 2011.

CRESWELL, J.W. Projeto de pesquisa: métodos qualitativo, quantitativo e misto. 3. ed. Porto Alegre: Artmed/Bookman, 2010.

DIAS, T. R. F. V.; NARDELLI, P. M.; VILAS BOAS, A. As competências empreendedoras: um estudo sobre os empreendedores ganhadores do prêmio TOP Empresarial. In: EGEPE ENCONTRO DE ESTUDOS SOBRE EMPREENDEDORISMO E GESTÃO DE PEQUENAS EMPRESAS, 5., 2008, São Paulo. Anais... São Paulo: EGEPE, 2008.

ESPINHA, P. G.; MACHADO, H. P. V.; RODRIGUES; R. M. I. Considerações sobre o empreendedorismo e a exploração de negócios no franchising. In: EGEPE ENCONTRO DE ESTUDOS SOBRE EMPREENDEDORISMO E GESTÃO DE PEQUENAS EMPRESAS, 4., 2005, Curitiba. Anais... Curitiba: EGEPE, 2005.

ESPINHA, P. G. et al. Fatores de Fracasso de Empreendimentos no Sistema de Franchising: um estudo exploratório. In: HOELTGABAUM, M.; MACHADO, H. V.; MACHADO, D. D. P. N. (Orgs.). Empreendedorismo em Franquias. Blumenau: Edifurb - Ed. da FURB, 2007. p. 91-129.

FEUERSCHÜTTE, S. G.; GODOI, C. K. Competências de Empreendedores Hoteleiros: um estudo a partir da metodologia da história oral. Turismo - Visão e Ação, v. 10, n. 1, p. 39-55, jan. /abr., 2008.

FILION, L. J. From Entrepreneurship to Entreprenology. 42nd ICSB World Conference held in San Francisco, California, USA, June/1997.

FLEURY, M. T. L.; FLEURY, A. Construindo o Conceito de Competência. Revista de Administração Contemporânea, São Paulo, Edição Especial, p. 183-196, 2001.

GEM. GLOBAL ENTREPRENEURSHIP MONITOR. Empreendedorismo no Brasil: relatório executivo 2012. Curitiba: IBQP, 2012.

HONMA, E. T.; TEIXEIRA, R. M. Competências empreendedoras em hotéis de pequeno porte: estudo de múltiplos casos em Curitiba, Paraná. Turismo - Visão e Ação, v. 13, n. 1, p. 52-80, 2011.

KAUFMANN, P. J.; DANT, R. P. Franchising in the Domain of Entrepreneurship Research. Journal of Business Venturing, v. 14, n. 1, p. 5-16, 1999.

LENZI, F. C. Os empreendedores corporativos nas empresas de grande porte dos setores mecânico, metalúrgico e de material elétrico/comunicação em Santa Catarina: um estudo da associação entre tipos psicológicos e competências empreendedoras reconhecidas. São Paulo, 2008. 126f. Tese (Doutorado em

SOUZA, M. A. M; TEIXEIRA, R. M. Competências Empreendedoras em Franquias: estudo de multicasos em Sergipe. Revista de Empreendedorismo e Gestão de Pequenas Empresas, v. 2, n.2, p. 3-31, 2013. 
Administração). Faculdade de Economia, Contabilidade e Administração. Universidade de São Paulo.

LENZI, F. C. et al. O desenvolvimento de competências empreendedoras na administração pública: um estudo com empreendedores corporativos na prefeitura de Blumenau, Santa Catarina. Gestão \& Regionalidade, v. 28, n. 82, 2012.

LIZOTE, S. A. et al. Empreendedorismo: uma investigação empírica acerca das relações entre competências empreendedoras e conduta intraempreendedora. In: ENCONTRO DA ASSOCIAÇÃO NACIONAL DE PÓS-GRADUAÇÃO E PESQUISA EM ADMINISTRAÇÃO, 36, 2012, Rio de Janeiro. Anais... Rio de Janeiro: ANPAD, 2012.

LUIZ, D. et al. Franchising como forma de negócio: um estudo preliminar no município de Tupã (SP). In: ENCONTRO DA ASSOCIAÇÃO NACIONAL DE PÓSGRADUAÇÃO E PESQUISA EM ADMINISTRAÇÃO, 30., 2006, Salvador. Anais... Salvador: ANPAD, 2006.

MAMEDE, M. I. B.; MOREIRA, M. Z. Perfil de competências empreendedoras dos investidores Portugueses e Brasileiros: Um estudo comparativo na rede hoteleira do Ceará. In: ENCONTRO DA ASSOCIAÇÃO NACIONAL DE PÓS-GRADUAÇÃO E PESQUISA EM ADMINISTRAÇÃO, 29., 2005, Brasília. Anais... Brasília: ANPAD, 2005.

MAN, T. W. Y; LAU, T. Entrepreneurial competencies of SME owner/ manager in the Hong Kong services sector: a qualitative analysis. Journal of Enterprising Culture, v. 8, n. 3, 2000.

MAN, T.; LAN, T.; SNAPE, E. Entrepreneurial Competencies and the Performance of Small and Medium Enterprises: An Investigation through a Framework of Competitiveness. Journal of Small Business and Entrepreneurship, v. 21, n. 3, p. 690-708, 2008.

McCLELLAND, D.C. Human Motivation. Cambridge: Cambridge University Press, 1987.MICHAEL, S. C. First mover advantage through franchising. Journal of Business Venturing, v. 18, p. 61-80, 2003.

MINELLO, I. F. et al. Competências e Características Empreendedoras dos proprietários das lojas de um Shopping Popular. In: ENCONTRO DA ASSOCIAÇÃO NACIONAL DE PÓS-GRADUAÇÃO E PESQUISA EM ADMINISTRAÇÃO, 35., 2011, Rio de Janeiro. Anais... Rio de Janeiro: ANPAD, 2011.

MORALES, S. A. Relação entre competências e tipos psicológicos junguianos. Florianópolis, 2004. 199f. Tese (Doutorado em Engenharia da Produção). Programa de Pós Graduação em Engenharia de Produção. Universidade Federal de Santa Catarina.

SOUZA, M. A. M; TEIXEIRA, R. M. Competências Empreendedoras em Franquias: estudo de multicasos em Sergipe. Revista de Empreendedorismo e Gestão de Pequenas Empresas, v. 2, n.2, p. 3-31, 2013. 
NEUMAN, W.L. Social Research Methods: Qualitative and Quantitative Approaches. 3. ed. USA: Allyn\& Bacon, 1997.

PAIVA JÚNIOR, F. G.; LEÃO, A. L. M. de S; MELLO, S. C. B. Competências empreendedoras em comportamentos de dirigentes de êxito socialmente reconhecido. In: ENCONTRO DA ASSOCIAÇÃO NACIONAL DE PÓSGRADUAÇÃO E PESQUISA EM ADMINISTRAAÇÃO, 27, 2003, Atibaia. Anais... Rio de Janeiro: ANPAD, 2003.

PAIVA JÚNIOR, F. G. et al. A contribuição das competências empreendedoras para a formação de dirigentes em sistemas de incubação. In: ENCONTRO NACIONAL DE ESTUDOS DA ENGENHARIA DE PRODUÇẨO, 26, 2006, Fortaleza. Anais... Fortaleza: ENEGEPE, 2006.

POLITIS, D. The process of entrepreneurial learning: A conceptual framework. Entrepreneurship Theory and Practice, p. 399-424, Jul., 2005.

RIBEIRO, B. B.; PRIETO, V. C. Franquia varejista como vantagem competitiva: múltiplos estudos de caso no segmento de farmácias e drogarias. Gestão \& Regionalidade, v. 25, n. 75, 2009.

ROCHA, F. B. Impacto da postura comportamental do franqueado e de sua relação com o franqueador no desempenho da franquia. Curitiba, 2010. $172 f$. Dissertação (Mestrado em Administração). Programa de Pós-graduação em Administração. Pontifícia Universidade Católica do Paraná.

SAUNDERS, M. N. K.; LEWIS, P.; THORNHILL, A. Research methods for business studentes. England: Pearson Education, 2000.

SILVA, V. L. S.; AZEVEDO, P. F. Formas plurais no franchising de alimentos: evidências de estudos de caso na França e no Brasil. Revista de Administração Contemporânea, Edição Especial 1, p. 129-152, 2007.

UCBASARAN, D.; WESTHEAD, P.; WRIGHT, M. The Focus of Entrepreneurial Research: Contextual and Process Issues. Entrepreneurship Theory and Practice. v. 25 , n. 4 , p. $57-80,2001$.

VESALA, K. M.; PYYSIÄINEN, J. Understanding Entrepreneurial Skills in the farm context. Research Institute of Organic Agriculture. Switzerland: Frick, 2008.

YIN, R. K. Estudo de caso: planejamento e métodos. 3. ed. Porto Alegre: Bookman, 2005.

ZAMPIER, M. A. Desenvolvimento de competências empreendedoras e processos de aprendizagem empreendedora: estudo de casos de MPE's do setor

SOUZA, M. A. M; TEIXEIRA, R. M. Competências Empreendedoras em Franquias: estudo de multicasos em Sergipe. Revista de Empreendedorismo e Gestão de Pequenas Empresas, v. 2, n.2, p. 3-31, 2013. 
educacional. Curitiba, 2010. 298f. Dissertação (Mestrado em Administração).

Programa de Pós-Graduação em Administração. Universidade Federal do Paraná.

ZAMPIER, M. A.; TAKAHASHI, A. R. W. Competências empreendedoras e processos de aprendizagem empreendedora: modelo conceitual de pesquisa.

Cadernos EBAPE.BR, Rio de Janeiro, Edição Especial, v. 9, p. 565-585, 2011.

ZAMPIER, M. A.; TAKAHASHI, A. R. W.; FERNANDES, B. H. R. Sedimentando as bases de um conceito: As competências empreendedoras. Revista de

Empreendedorismo e Gestão de Pequenas Empresas, v. 1, n. 1, jan./abr., 2012.

ZARIFIAN, P. Objetivo competência: por uma nova lógica. São Paulo: Atlas, 2001.

Artigo recebido em: 03/06/2013. Artigo aprovado em: 31/08/2013

SOUZA, M. A. M; TEIXEIRA, R. M. Competências Empreendedoras em Franquias: estudo de multicasos em Sergipe. Revista de Empreendedorismo e Gestão de Pequenas 